\title{
The Cynical Public: Claims About Science in the Discourse on Hydrofracking
}

\author{
by Elizabeth Seale and Gregory Fulkerson
}

SUNY Oneonta; SUNY Oneonta

Sociological Research Online, 20 (3), 4

$<$ http://www.socresonline.org.uk/20/3/4.html>

DOI: $10.5153 /$ sro.3591

Received: 10 Sep 2014 I Accepted: 23 Feb 2015 I Published: 31 Aug 2015

\begin{abstract}
This content analysis of newspaper articles and online social media from English-speaking sources on the topic of 'fracking' interrogates the use of scientific legitimacy in claims-makings and how public understandings of science develop through these media. In both forms of media, science is invoked in one sense as rational and objective to either neutralize or support emotionally-charged accounts and fears of hydraulic fracturing dangers. In another sense, however, science is viewed as a bureaucratic tool used at the will of government and business interests and easily corrupted to support ideological or interest-based positions. Claims regarding science typically follow ideological positions rather than the reverse - the 'science' that supports fracking as safe is called into question by those skeptical of fracking, while the anti-fracking position is designated as 'anti-science' by those who favor fracking. These strategies as they play out in the media serve to spread uncertainty, heighten cynicism, and undermine public confidence in science. An understanding of science as incomplete and cumulative, however, lends itself to the precautionary principle.
\end{abstract}

Keywords: Science, Hydraulic Fracturing, Fracking, Claims-Making, Media, Risk

1.1 Like other publicized debates over issues such as climate change, genetically-modified products, and nuclear energy, the media discussion of unconventional shale gas development, popularly known as fracking, invokes 'science' both as a source of credibility and an object of skepticism. Public concern over fracking rose dramatically following the release of the influential documentary, GasLand, by Josh Fox, as shown later in the analysis. Our main focus lies in the exploration of what role there is for science in such public debates. The issue of unconventional shale gas development is shrouded in uncertainty, thus rendering cost-benefit estimates very difficult, and has resulted in what Ten Eyck and Deseran (2004) refer to as chiastic media coverage-two parallel lines of media coverage moving in opposing directions. With regard to shale gas development, one such line touts economic gains and energy independence that it may bring, while the other warns of impending environmental catastrophe and threats to human health. In the media, science has been used both to warn against technological dangers (e.g., global warming), and to assure that there is nothing to fear (e.g., from genetically-modified food) (Wander and Jaehne 2000). Such outcomes are typical in a world defined in Beck's (1995) terms as a 'risk society,' whereby uncertainty becomes a normal state of affairs.

Dewey (1927) discussed this issue at length in The Public and its Problems, where he concluded that there is a need for clear and uncorrupted communication flows between those with expertise and the wider public if we are to avoid the creation of a technocracy and allow a democratic process to unfold. Reference to science plays an important role in public debates over technological development and risk (Christidou Dimopolous, and Koulaidis 2004; Saleh 2008; Anderson et al. 2011), and journalists and print media can serve as key gatekeepers (Schafer 2011). However, we suggest that online social media can potentially play an influential role in shaping public discourse, in a manner that exceeds the potential of traditional print media. This is because social media in general provide for active participatory communication about the issue at hand, rather than the more traditional passive participation that accompanies reading print media sources-the exception is the op-ed piece where citizens can express their views publicly. 
unconventional shale gas development and includes all English language news articles identified in the LexisNexis database that includes 1000 articles. This returned results primarily from the United States, and many originating from other nations, including Canada, Australia, New Zealand, South Africa, Ireland, and the United Kingdom. The social media analysis time frame ranges from 2006-2013, and includes content from Facebook and Twitter primarily, captured through query-based search components (i.e., a series of search terms that work simultaneously to identify relevant social media content) available through the online social media collection tool, Trackur. These time frames were selected based on media activity - the first available news articles and social media messages marked the starting points. We examine these sources qualitatively to determine how science is being represented and used by members of the public. A high level of uncertainty is engendered by early journalistic accounts and social media references, but the reactions to this uncertainty diverge according to particular understandings of science.

\section{Background on Hydraulic Fracturing}

2.1 New methods of unconventional gas and oil drilling involving hydraulic fracturing have created widespread economic activity as well as considerable public resistance and concern. These methods, though relatively new to the industry, are used in roughly 60 percent of existing wells (Montgomery and Smith 2010). The process involves first drilling deep vertical wells that then bore horizontally, and are finally filled under extreme pressure with water, sand, and chemicals to break up rock and force out gas that is in turn captured and stored (Brown 2007). Technically, 'fracking' is shorthand for the specific aspect of the process associated with highpressure water/sand/chemical mixture used to break up rock. In everyday as well as social movement discourse, it has come to be synonymous with all aspects of the unconventional drilling process used to access shale gas, tight gas, and coal seam gas. Land-owners, communities, regions, and nations have responded with reference to a range of values, including both a desire to maximize the economic and energy benefits of gas and oil along with competing desires to protect the environment and human health from the potentially dangerous byproducts of the process.

2.2 Proponents insist that the technology is tested and safe while offering potential benefits to the economy and energy supply that far outweigh the risks. They point out that reserves of gas may be in excess of 4000 feet below the surface, while groundwater supplies typically do not exist below 850 feet (Zoback et al. 2010), thus arguing that depth provides a barrier of safety. The promise of employment and much needed tax revenue in otherwise depressed rural areas along with generally cheap energy and less reliance on foreign energy are also among the top reasons hailed by proponents.

These claims have been countered by objections primarily originating with environmental and health groups, who point to a range of observed and potential problems including water contamination from toxic chemicals in fracking fluid, thought to include VOCs (volatile organic compounds) such as toluene, ethyl benzene, and xylenes. Many of the chemicals believed to be in use are carcinogenic or threaten endocrine disruption. Moreover, the drift of methane into groundwater can make it flammable, as was infamously shown in the documentary Gasland, wherein residents were filmed holding lighters under their kitchen tap and starting a blaze. In addition to contamination are concerns about the high demand for and usage of scarce water supplies. Other concerns are related to exposure to naturally occurring radiation stored in the earth, and the initiation of earthquakes from drilling (BBC 2011). Finally, environmental critics point out that continuing to pursue fossil fuels such as natural gas will undermine efforts to develop clean energy alternatives such as wind, geothermal, and solar energy (Lustgarten 2011). [FG1]

Caught in a firestorm of expert claims and counterclaims, the public reaction has been mixed. In ongoing public opinion research by Gunsallus, Martin, and McLaughlin (2013) in the Marcellus Shale region of Pennsylvania in the United States, respondents suggest many locals do not know who to trust, and as a result, local gas industry workers feel they need to inform others since they have an insider's view. Similarly, Luloff, Willits and Theodori (2013) have shared their findings that residents in 2012 were more likely to have an opinion than in several years prior, and to agree that drilling poses a threat, but also more likely to agree 'we should move forward' with shale gas development. Finally, Evensen, Clarke and Stedman (2013) point out that a new shale basin is created nearly every week, and that newspapers are still the most used source for information on gas development in the Marcellus Shale area. Their study, involving a sample of four regional newspapers from 2008 to 2011 and interviews with journalists, revealed oversimplified juxtapositions of environment versus economic impacts in newspaper coverage-consistent with the hypothesis that media coverage of unconventional drilling has been chiastic. 
distrust, although the recent public survey data does not seem to support this claim as a national phenomenonit may be the case in particular locales. A number of local and regional governments have already made decisions to institute moratoriums or permanent bans on fracking technologies. In other locations, such a precautionary stance is viewed as extreme and the decision to allow fracking has been made. In this context, media-both print and social-play a crucial role as having the power to shape and direct the debate, decision making, and subsequent action. Furthermore, the credibility and role of science are continually constructed through this debate.

\section{Research Questions: Science, Media and the Public}

3.1 In this section we provide a discussion of literature pertaining to the interplay of science, media, and the public, highlighting three primary research questions. Our questions explore issues dealing with uncertainty or inconclusiveness of evidence, the process of deliberating risks and benefits, and the role of science in public discourse.

We begin with a consideration of how the public adapts to uncertain conditions. Several decades ago Brian Wynne argued that it is becoming more difficult to distinguish between safe and unsafe conditions. Despite the pressure on technocrats to assure the public by following set rules, 'diversification and extension of markets and implementation settings (for example, chemical plants and nuclear reactors in the underdeveloped countries) creates more complexity and potential fragmentation' (Wynne 1988: 156). In addition, Norton (2005) argues that the standard Risk Assessment/Risk Management model routinely used by the Environmental Protection Agency in the United State to assess risk assumes that all science is complete and all value judgments are final when it is time to make recommendations. These sets of conditions are highly unrealistic, and with regard to values, the public-who must ultimately live with the consequences - is left out of the discussion. In turn, a priori and hidden value judgments are left unexamined (Norton 2005; Saleh 2008; Fitzgerald and Rubin 2010). This argument complements Beck's $(1995,2009)$ ideas about living in a 'world risk society.' Beck questions why the burden of proof is routinely placed on the public to show that something is dangerous, when it would be much less precarious to require experts to bear the burden of proving the safety of a new technology prior to introducing ita view generally regarded as the precautionary principle. Beck (2009) categorizes the institutional claim to both competency and impunity as a core contradiction in society and directs attention to the profound uncertainty that characterizes modern society in the face of these risks and the science that drives and explains it (2009:194):

Risk and non-knowledge prompt the call for security and lead to new insecurities and uncertainties in the general groping about in the fog of insecurity and uncertainties. Moreover, the undecidability of problems, which nevertheless have to be decided, is growing along with the pressure to make decisions (Adam et al. 2000; Beck and Lau 2005).

What Beck, Norton, and other scholars converge on is the notion that although scientific methods provide valuable information and valid evidence, expert voices should not drown out public concerns. Science is always a work-in-progress, and although debate in a democracy should be informed by scientific evidence, the uncertainty inherent in science should be recognized. How is this complexity represented in the discussion about shale gas and oil development as a source of energy and industry with some unknown level of risk? Thus, we have our first set of research questions: Is uncertainty or inconclusiveness represented in the debate over the dangers of fracking? When and how is evidence contested and/or judgment suspended?

3.4 Next we examine how the potential risks and benefits are debated publicly, using the notion of chiastic coverage as framework for understanding. Metaphors, as Christidou, Dimopolous, and Koulaidis (2004) point out, are epistemological tools. In their examination of Greek newspapers and popular science magazines, technoscience is presented as expanding the frontiers of knowledge in many cases, and as a 'dipole of promise and/or scare' (347). Similarly, topics of many health and science reports lend themselves to negative interpretations, or an emphasis on risk (Reisch and Speigelhatlter 2011). On the other hand, the reference to 'science' has been used to negate concern. In a study of the coverage of the debate over genetically-modified food in Australia, Saleh (2008) argues that even though there was some useful debate, journalists' coverage of the risk tended to reify and support the 'sound science discourse' that granted ultimate authority to scientific experts. On one side, GM proponents accused the other side of being 'anti-science' and 'told dissenting scientists concerned about the adequacy of safety tests to "put up or shut up"' (Saleh 2008:236). Although journalists seemed aware of the limitations of science, they still tended to defer ultimately to scientific authority and left technical knowledge unexamined (Saleh 2008). Hidden value judgments and assumptions about the science were left unexaminedfor instance, that 'science knows all there is to know', that the benefits outweigh any unknown risk, and that lack of evidence of harm could be interpreted as safety (Saleh 2008). In such debates over risk, where should the burden of proof lie? Here we have our second set of research questions: Is lack of harm interpreted as safety? How are risks and benefits weighed? For what purposes - rhetorical or otherwise-is science invoked? Has coverage been chiastic? 
Finally, we consider the idealized role of science in public discourse as represented in media coverage. Science is often characterized as a neutral, value-free guide for policy in ways that may be problematic. Political and economic actors may use science for their aims, and non-governmental organizations commonly bring in counter-experts on different issues to support their agenda (Schafer 2011). Competition for providing science information has increased. As Schafer (2011) discusses it, the Public Understanding of Science (PUS) model views science as superior to other forms of knowledge, and postulates that scientific literacy will be linked to positive sentiments regarding scientifically-grounded development efforts. The goal of journalism then, according to this model, should be to cultivate relationships with scientific authorities and rely on expert consensus in debates (Saleh 2008:234). However, the 'fourth estate' tradition of journalism is an alternative model (Deuze 2005), which charges journalists with the watchdog role (Saleh 2008). As an academic model, the PUS model has been heavily criticized, giving way to other models including the mediatization model which recognizes that science and the media build on one another. The media often tend to sustain the expert imperative, but can also create spaces for it to be challenged (Tulloch and Zinn 2011).

One strategy among journalists, perhaps particularly when resources are low, is to simply provide points from both sides of the story with little analysis. The balancing of competing claims actually gives more coverage to institutional sources, but according to Saleh (2008) can absolve journalists from making a stand. For American journalists, this is considered standard practice and to do otherwise is to violate the assumptions of the discipline. Moreover, financial and time pressures in everyday news production means that journalists are dependent on others, and they may resist responsibility for validity of claims by using experts to construct 'facts' particularly when they do not have the expertise to evaluate claims, as with nanotechnology. The responsibility for the validity of a claim 'is displaced by attribution' (Cooper and Ebeling 2007: section 2.3). Again however, as Tulloch and Zinn (2011) point out, news media has incentive to highlight risk, as well.

Despite the various ways in which top-down media may present science, technology, and risk to the public, the public are neither passive nor merely receptive. Christidou et al. (2004) for instance are quick to point out that the public does not necessarily share the same general view of science as represented in popular print media. The media is often critiqued as amplifying or sensationalizing risk, but there is also 'a parallel discourse that is very sceptical' that shows up particularly in op-eds and feature pages (Reisch and Speigelhatlter 2011:48). Research has also shown that the media affect people differently based on a number of factors (age, interest in science, gender, religiosity, etc.), but for many science seems to be a non-issue on which they have no strong opinions, and they tend to rely on their own preconceptions rather than accepting the media's approach (Schafer 2011:406; citing Priest 1994, 2008). Even strong slants in the media do not predict public opinion \$chafer 2011). Using survey data in the U.S., Anderson et al. (2011) find that deference to scientific authority is also related to trust in governmental agencies, but so is having a participatory attitude towards science, perhaps because they view the government 'as a cooperative actor in that decision-making' (232). This, however, may be particular to the U.S., where the public tends to have more faith in technology and the mass media operates in countryspecific ways. They also note that trust can alter, and trust in scientific expertise may not be stable. Schafer (2011) suggests the public have become increasingly critical of science, not because they understand it less, but because it has been in the public eye more, and Saleh argues that '[c]itizens are becoming increasingly alienated by the unaccountable value judgments of so-called sound science decisions and are demanding more participation in technological futures' (2008:234; citing Wynne 2001 and Levidow 2002). The notion of chiastic coverage leads us to ask if there are different ways in which coverage of the issue depends on and invokes scientific legitimacy. Our third set of research questions include: What role is delegated to science and to the public? Are public concerns about shale gas development dismissed, and if so, on what grounds?

3.8 While the degree of participation that the citizens actually have in policy is a separate empirical question, methodologically, such participation is an important component to include in our analysis. Tulloch and Zinn (2011) argue for a participatory approach in examining the media's link to the public. We also recognize that the media is very heterogeneous, including a variety of forums such as the internet, google, blogs, and discussion groups. Moreover, it is not a one-way stream of information. Thus, in our analysis of the debate, we examine not only print news articles and opinion editorials, but also online social media sources such as Tweets and Facebook posts as a supplemental source of data.

\section{Methods}

4.1 Our study therefore encompasses two separate sets of data: newspaper and social media content. Our selection of newspaper articles was obtained from the LexisNexis Academic Search Complete database, searching through all English language newspapers for the term 'fracking.' We found that it was such a pervasive term that there were few articles about the subject that used alternative terminology, such as the more technical 'hydrofracking', 'hydraulic fracturing', or the alternate spelling, 'fracing', that some in the industry prefer. The time 
period for the investigation dates from 2005 through October of 2011. This population of articles captures the beginning of the coverage of fracking and illustrates some level of sustained interest. Several news stories were repeated and re-printed on different occasions. After duplicates were excluded from the analysis, a total of 748 unique articles remained. Of these, we conducted open-coding on the odd-numbered articles, totaling 374 unique documents.

The Lexis-Nexis search for news articles resulted in the identification of nations and regions around the world where the issue of fracking has become newsworthy. These include the United States (360) followed by South Africa (172) and Canada (93). In the next tier the articles are divided between the U.K., Australia, Ireland and New Zealand, while one article is from India. In the United States, there are multiple regions where fracking is taking place, and news coverage ranged from the Marcellus and Utica shale regions near Pennsylvania and New York stretching down to the Virginias, over to the Plains states of the Dakotas (Bakken Shale), to Colorado where fracking has long been underway, and to the South in Texas and Oklahoma (Eagle Ford Shale and Barnett Shale). Nearly all of the attention in South Africa is on a sensitive region called the Karoo, where some of the most inflamed rhetoric surrounding the issue can be found. In Canada, focus has been on some of the shared shale deposits with the United States, including those found in Quebec (where fracking is banned) and westward to Alberta and British Columbia in geologic areas that are shared with the Plains States. In the U.K., attention has been on Wales primarily where the news reports industry ambition to drill exploratory wells. Attention has also been on Ireland, where the discussion has been less regionally situated. In Australia, the focus has been on Queensland and New South Wales, where there are deposits of Coal Seam Gas (CSG). Given the global attention paid to the issue, and our comparison to English-written social media sources whose national origins are not identifiable, we choose to keep the small number of articles from the second tier rather than restrict our analysis to North America and South Africa.

4.3 Coding and analysis proceeded in three main stages. Initially, to acquaint ourselves with the content of the news articles, we used Atlas.Ti to identify central emergent themes that cut across articles. Four coders conducted open-coding among the articles with an inductive orientation to identify central themes among proand anti-fracking arguments, as is characteristic of the grounded theory approach detailed by Charmaz (2006). This approach involves an openness to meanings in the data (Strauss and Corbin 1990; Esterberg 2002) that we enhanced by beginning with four separate coders. Following this grounded approach, the four coders discussed the emergent themes in relation to the extant literature examining media coverage of complex issues. The themes were grouped into four main categories: risk, impacts, actors, and knowledge claims. Coders then proceeded to take command of these topics and coded articles in the sample accordingly, constituting the second stage of coding and analysis. For instance, for the topic of risk, codes included risk-time-wait, risk-timedon't wait, risk-burden-prove safe, and so on. In addition, all mentions of the words scien*, technology, and evidence were queried and coded with terms like science-governance, science-legitimacy, and evidencecontested. Open coding continued as well, although few new categories after this point proved important. Coder inter-reliability tests were conducted for this second phase on 25 documents by the two primary researchers for what became the primary codes for analysis. These include the following 25 codes, with frequencies across coded documents indicated in parentheses:

- evidence (142)

- evidence-alternative (7)

- evidence-contested (10)

- impact-economy (130)

- impact-energy (100)

- impact-environment/resources (358)

- impact-health/safety (221)

- risk-attitude-neutral (76)

- risk-attitude-optimistic (222)

- risk-attitude-pessimistic (517)

- risk-burden (75)

- risk-burden-prove not safe (42)

- risk-burden-prove safe (136)

- risk-time-don't wait (17)

- risk-time-wait (71)

- public can't understand (19)

- science-governance (56)

- science-legitimacy (109)

- science-limits (32) 
- tech-known (38)

- tech-risks (81)

- tech-unknown (54)

Inter-reliability on specific codes was assessed at 77\%. Most discrepancies were such that the "quotation" (Atlas.Ti terminology) at issue was coded as a similar code, or else reflected differences in gauging the intent of the writer. At the subsequent stage, intent of the writer was examined more strictly. Finally, query reports on the primary codes were printed out (separated by national origin and whether the document was an editorial or news article to explore possible differences), and coding by hand was used in this third stage to examine trends and countertrends more closely, from which analysis memos developed (see Charmaz 2006).

4.5 As a complement to our newspaper analysis - and to explore new techniques in analyzing public datawe also consider social media sources. The social media data examined here are from a combination of sources, about two-thirds of which are based in Twitter, while the remaining are from Reddit, Youtube, Wordpress, Flickr, Google+, Facebook, and web blogs. Only messages that were publicly available were accessible to the social media search tool, Trackur.

4.6 Trackur provides search capabilities through combinations of keywords, and each keyword search can be saved so that new social media can be tracked and aggregated into a data file. A dedicated Trackur ( http://www.trackur.com) account was used to search for several simultaneous queries across multiple sources. The query searches used in this analysis include:

- fracking

- \#fracking

- \#hydrofracking

- hydrofracking

- hydraulic fracturing

- hydrolic fracturing

4.7 Datasets were generated from each of these individual searches, downloaded on a weekly basis to capture new content, and then combined. The combined files from each search term were then merged to create a file that included content from each search terms using Microsoft Excel. Once the data were combined, the duplicates were removed, and this resulted in a final dataset of 30,990 online text-based social media messages. The date range of the combined dataset is from 28 September, 2006 to 12 June, 2013. However, the data collection process began on 8 December, 2012 and ended 14 June, 2013. Therefore, the data that precedes the starting point of the analysis period includes only items that remained accessible online during the analysis period and thus do not capture all historical data. Indecipherable messages were excluded (e.g., a Tweet that was nothing more than hashtags, at-replies, or links, but no clear thought expressed about them), yielding a final dataset of 30,969 messages. We would have preferred to find sources that date back to the beginning of the newspaper time frame, but the ability to conduct historical searches of social media is currently restricted and not available to Trackur. Examination of potential sources of historical Twitter data was found to be priced outside of the constraints of this budget of this study and included a number of restrictions that would have prohibited primary analysis (i.e., third party providers of historical Twitter data restrict access to that data so that it cannot be bought and then subsequently resold). The resulting time difference between the news and social media analyses is a limitation of this study that we were unable to fully address, but as social media activity was very slight prior to 2006 we do not anticipate this to have major consequences for the analysis.

4.8 The data used in this analysis did not include identifying information about users or their geography, thus protecting identity. The variables in the dataset included the URL of the data source, the 'description' that refers to the intended message (e.g., a Tweet), the date of the message, the media type (image, news, blog, etc), and the sentiment of the message as positive, negative, or neutral.

4.9 The dataset of social media messages that was created using the techniques discussed above were analyzed using IBM SPSS Modeler software, using text mining procedures. Of particular use was the Text Analytics tool. This tool begins by extracting 5000 of the most relevant concepts found in the individual textbased messages. Next, using a natural language algorithm, the software automates the building of hierarchical categories. Within each of these categories are placed different concept and phrases. As this automated process is not perfect, the data analysis requires what is referred to as 'curation'-automated coding results are not 
simply accepted at face value, but rather are examined closely and corrections and modifications are made as required. As an example, one of the messages suggested that 'pressure' should be put on the government to implement regulations on fracking, and 'pressure' was erroneously categorized as a physics concept. The natural language algorithm is not fully able to account for metaphor, simile, or the general context of messages. Generally, the categorization was found to be efficient, particularly in comparison to manually coding 30,990 messages (a virtual impossibility). Through the curation process, new categories could be created, existing categories could be deleted or renamed, and individual concepts and phrases could be manually moved between categories. Through the process meaningful categories emerged that took a similar shape to those categories found in the newspaper content analysis, facilitating comparisons, as illustrated later in the paper in table 1.

4.10 We compared this method of categorizing data with the researcher-driven process by taking a random sample of 500 social media posts and conducting coding by hand. Some of the codes used for the newspaper documents did not apply well to the social media posts, particularly the shorter posts. The social media posts overall provided far less depth of data with which to work. Coding using these two different methods overlapped by about $25 \%$ when it came to general position conveyed by the post, and whether or not science was invoked in the actual post. About $66 \%$ of this sample consisted of tweets, with Facebook posts second at $13 \%$ and News/Blogs third at $7.6 \%$. While the text analytics tool may be useful for constructing emergent themes and categories, the frequency and nature of the categories are not well accounted for by this process. Researcherdriven coding becomes necessary for detecting humor, irony, sarcasm, mockery, and other nuances of human communication. Thus, we rely on the hand-coded results for closer analysis, while also presenting the results of SPSS Text Analytics tool.

\section{Analysis and Results}

5.1 In this study we interrogate the nature of science-based claims-making with regard to the hydraulic fracturing of shale gas. Following some descriptive results, we focus on the use of science in claims-making as a basis for legitimacy. We find that in some cases people tend to claim scientific legitimacy to support their orientation one way or the other, although such claims tend to be highly generalized and suggestive that the science is complete and closed. On the other hand, we find a good deal of skepticism towards science. Much of this skepticism grows out of the belief that scientific claims are corrupted. Corruption is thought to be driven by political interests, industrial interests, or a hidden media agenda that is sometimes referred to simply as 'Hollywood'. Further, scientific claims are believed to be clouded by or disregarded due to emotion and ideological thinking. Different claims-making tends to regard the science on the effects of fracking as either 'junk' or 'pseudo' science, or to portray science as 'solid' and the ultimate anti-dote to ideological claims.

\section{Sentiment and Presence of Science in Media Discourse}

5.2 While coding newspaper articles, we noted a tendency in editorials in particular to emphasize the dangers of fracking. Thus we thought it useful-albeit crude-to categorize the general sentiment explicitly conveyed in each news article. We realize the complexity of sentiment and only provided a positive or negative code if there was a consistent position in the article. If multiple and conflicting positions were presented, the article was coded as neutral. As a result of this method, the neutral category may be larger than if alternative strategies were used, such as coding multiple positions within the same article. The notion of chiastic coverage is that the media presents two conflicting lines of coverage, and this coding scheme allowed us to empirically investigate this possibility.

The results of this sentiment coding are shown in Figure 1, where we see that explicitly pro-fracking new articles made up 11 percent, while 43 percent were anti-fracking, and the remaining 46 percent could be considered neutral. Among neutral articles, many reported technical issues related to fracking, or expressed statements both favorable and unfavorable with no clear predominant preference. In the sample of social media posts, $9 \%$ were favorable to fracking, $43 \%$ were unfavorable, and $27 \%$ were neutral posts. An additional $18 \%$ were coded as unknown, because it was too difficult to discern from the post itself whether fracking was being advocated, opposed, or discussed in a neutral manner, and the remaining $3 \%$ were not applicable because 'frack' was used but the substance of the post had nothing to do with hydraulic fracturing or shale gas development. Thus, in spite of fundamentally different media types and coding procedures, we find a level of support for fracking that differs by only 2 percent between newspapers and social media. The large number of neutral category rankings clearly presents a problem for the chiastic coverage hypothesis - the opposition to hydraulic fracturing has been much more prevalent than support, as has a neutral position. This neutrality complicates what might otherwise be viewed as chiastic coverage. [FG2] 


\section{Position on Fracking}

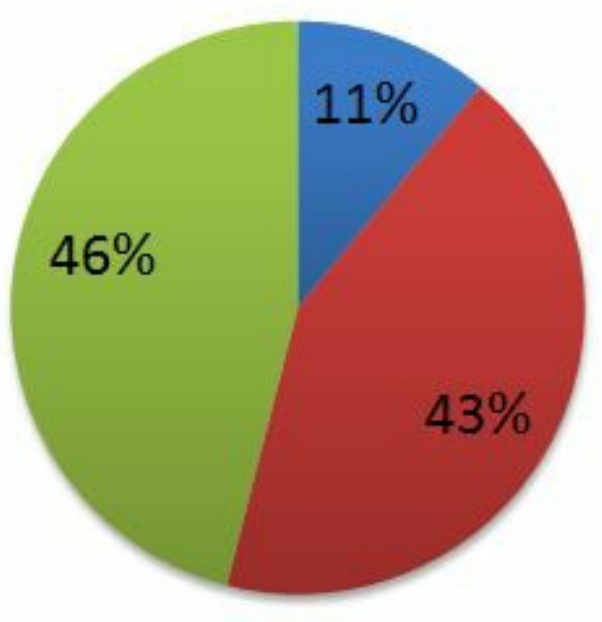

Support

Oppose

Neutral

\section{Newspapers}

\section{Position on Fracking}

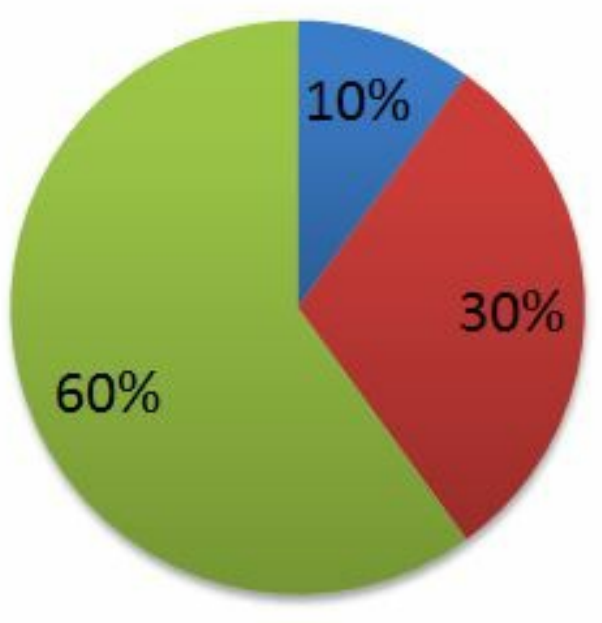

Support

Oppose

Neutral

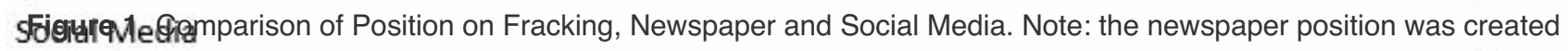
through manual content analysis of news articles; the social medial position results from an automated text analytic process using IBM Modeler.

5.4 The newspaper media are about twice as likely to invoke science in the discussion of fracking as compared to social media. Creators of social media posts-people using such technologies as Twitter and Facebook - were less likely to invoke science-based claims than journalists and other contributors to newspapers. Immediately this sheds light on one inherent difference between media types, with the news sources attentive to science, perhaps adhering to ideals of journalistic integrity or simply reflecting the greater space for such discussion. Nevertheless, at roughly one in seven articles, reliance on science to discuss fracking is far from ubiquitous. The relative infrequency of science-based claims in social media is itself an interesting statement about public dialogue, although we are aware that social media users are not a fair representation of society, maintaining for instance a well-known age bias towards youth. Another likely reason that science is rarely invoked in social media is the limited space available for a Twitter Tweet-roughly 140 characters. In fact, the nature of Twitter may constrain debate. Not only is space for argument limited within each tweet, but diversity of information and opposing arguments are inhibited by the organizations and people whom one chooses to follow in the first place. Thus, social media like Twitter should be interpreted with a mind as to how information is shared -the intended targets of tweets as well as the intent and interests behind the construction of a person's feed. 
The intention of posting social media content may vary with respect to either expressing ones ideas versus initiating a dialogue. Whereas weblogs and Facebook posts are more likely to be an expression (more like an editorial in a newspaper), Tweets and online forums are often prompts to initiate a dialogue and may be less developed forms of self-expression and more a way to spark debate and encourage others to express their ideas. relative to other issues, science ranks somewhere in the middle in fourth place for newspapers and fifth place for social media. The most discussed issues in the fracking news and social media are the environment as well as the law and politics components of fracking. Social media were more focused on the economics of fracking as compared to the news media, as shown in the thematic rankings.

Table 1. Comparison of Content Categories in Newspapers and Social Media

\begin{tabular}{|c|c|c|}
\hline Category & Newspapers (Percent) & Social Media (Percent) \\
\hline Environment & $42.7 \%(1)$ & $23.67 \%(1)$ \\
\hline Law and Politics & $36.7 \%(2)$ & $21.36 \%(2)$ \\
\hline Debate, Protest, & $35.8 \%(3)$ & $4.78 \%(6)$ \\
\hline \multicolumn{3}{|l|}{ Activism } \\
\hline Science & $16 \%(4)$ & $5.32 \%(5)$ \\
\hline Health & $10.6 \%(5)$ & $2.73 \%(8)$ \\
\hline Fracking & $9 \%(6)$ & $11.82 \%(4)$ \\
\hline Economics & $7.2 \%(7)$ & $13.41 \%(3)$ \\
\hline Community and & $3.4 \%(8)$ & $3.38 \%(7)$ \\
\hline Housing & & \\
\hline
\end{tabular}

Note: these are not mutually exclusive categories, and thus may overlap.

\section{Uncertainty: Junk Science vs. the Wait-and-See Approach}

5.6 The public struggles with the uncertainty of the science of fracking. We presume this to be a common state of affairs for a technologically advancing society addressing risk; thus, we look first at how voices in the print and social media deal with this uncertainty. Two different reactions are identified: junk science accusations versus a wait-and-see approach. Charges of junk science or pseudo-science as opposed to solid, real, or true science are often predicated on the notions that good science is inherently anti-corrupt, anti-myth, anti-emotion, or anti-ideological. When being discredited, the specific claim may be called 'science fiction' or 'junk science.' Charges of junk science are being flung from both sides of the debate and in generalized ways that are hard to refute because they do not cite specific studies or ways of studying. Among those posts and articles favorable to fracking, one common strategy is to construe the opposition as anti-science, overly emotional, or out-of-touch. Those who oppose fracking are termed, for instance as 'enviro-mystic[s]' and 'enviro hypocrits'. regarded as incomplete. In both the social media and newspaper media we found an expression of the idea that decisions about fracking should be delayed until we have a better scientific foundation. In other words, as it is sometimes put, we need to 'get the science right.' There were several ways in which inconclusive results on the dangers of fracking were used. One interpretation was to emphasize the need for caution, since we simply do not know. Another interpretation gave permission to move ahead with the technology. In some cases, frustration over ambiguous evidence was expressed. 
associated with wading through the available scientific data. For many, it is clear that we are not yet ready to make an informed decision about fracking because the science is incomplete and inconclusive, as expressed in this statement made in an editorial: 'Until there is conclusive evidence that fracking will not impair groundwater, our policy should be precautionary to protect this resource.' In the social media, there were likewise widespread examples of reluctance to form a position due to the inconclusiveness of the science of fracking and a need to get the science 'right' before moving ahead: 'Minister Attwood said: 'I have repeatedly said that it is essential to get the science right." See additional examples in Appendix A. Although not always the case, we sometimes see a call for public participation. In such statements, public participation is represented as an important part of the process of making decisions. However, we also see scoffing at the ability of the public to participate in decisionmaking, as discussed more below.

\section{Interpreting Evidence}

In some comments science is exalted as the ultimate basis for legitimating a position for or against fracking. Examples of using science for legitimacy could be found on both sides of the debate. Whereas editorial writers appeared to be more likely to criticize studies of hydrofracking as 'junk' or as unavailable, mainstream journalists were apt to stick more closely to science as legitimate source. In social media examples on both sides of the debate claims that the 'science is in', in other words that the science is conclusive and supports a particular position. For instance, 'the science is in, and hydrofracking is safe' and 'the science \& facts show it's too dangerous and risky' occur in the social media data. Such examples demonstrate a tendency to invoke science to legitimate claims in highly generalized ways that suggest we have reached completeness and closure in terms of scientific investigations of the impacts of fracking. Science is even presented in one case as defining human rights.

5.10 Media containing references to specific studies were more difficult to find. Some that were discovered include research on the safety of drinking water as well as on the threat of earthquakes. Specific references to studies were sometimes used in conjunction with a link to a website that discusses the study, and sometimes specific details about the researchers and/or agencies involved are offered. These references at least invite informed debate about the merit of the studies in question, whereas the more general claims of scientific completeness and closure offer little room for debate. Nonetheless, in one example referencing 'the Duke study,' this specific study was also mentioned by editorialists and journalists on both sides of the debate as evidence that there either is or is not a problem, illustrating the ability of some scientific evidence to be interpreted in multiple ways.

5.11 One of the major issues reflected in these data include the issue of interpreting 'lack of evidence.' As discussed above, conflicting evidence is reported and no consensus appears to exist in journalistic reports of this time period. Thus, it is easy to claim a lack of evidence. But how is this interpreted? Does 'no evidence' of danger mean that fracking is safe? Does it simply mean that fracking hasn't been proven to be safe? Although sometimes the idea that there is a lack of evidence is hotly contested in assertions that in fact evidence for the negative impacts of fracking does exist, we see a reoccurring trend in efforts to interpret the lack of evidence. There are two primary ways for the public to interpret it: (1) fracking is safe, or (2) fracking is not necessarily safe, but dangers have not been observed scientifically. For example, when the EPA said there was no confirmed evidence of fracking contaminating water, the anti-fracking voices claimed that that was because the studies had not been done, NOT that they had been done and revealed this conclusion. However, although advocacy journalism and skeptical editorials made such points, mainstream journalists did not seem to pick up on it-they did not ask industry advocates, scientists, or other experts whether tests had shown that it could not occur as opposed to tests not showing that it could occur.

5.12 Scientific evidence was also challenged at times with the presentation of alternate forms of evidence. This most often came, not in direct confrontation with scientific results, but rather in light of lack of scientific confirmation of negative impacts. In newspapers, anecdotal evidence, online postings, and circumstantial evidence are at times presented as valid, especially among anti-fracking editorials or locals quoted in standard articles. One editorialist wrote, 'overwhelming circumstantial evidence from thousands of contamination cases points to fracking.' In another example, the editorialist quoted an anti-fracking activist as saying that, 'the stories are true...they are people's lives...the evidence is there, and people are living that evidence.' Such evidence is not overtly presented as superior to 'science' conducted by experts, but is viewed as convincing nonetheless. This, however, provides some ammunition for fracking supporters who argue that anti-fracking opinions are based on non-scientific anecdotes and gossip. One journalist noted that the '[o]il companies defend [fracking] as harmless and essential to the country's energy supply. Industry representatives and some lawmakers have decried an ongoing federal study of the practice as biased and inspired by anecdotes as opposed to science.' Additional examples can be found in Appendix A. 


\section{The Corruptibility of Science}

5.13 The tendency to invoke science to legitimize claims in generalized ways that imply closure and completeness may hinder the ability to meaningfully incorporate science into public discourse. The perceived ability of the public to discuss science depends on remaining free from corrupt influences. Yet, science is also represented as being value-free. One quotation in a news article exemplifies the view that science is the only way to avoid corrupt biases: 'Paying attention to regulations and scientific data is the only way to stay unbiased, he said.' Perhaps the overall infrequency of science based claims (as shown earlier in Figure 3) - particularly in social media - is itself a reflection of distrust in the ability of the public to grasp science, as suggested in research by Saleh (2008) and Schafer (2011). It seems that experts in particular express caution in allowing the public into the debate, and may attempt to intimidate them through reminders of their lack of qualifications. Though infrequent (occurring about fifteen times across 374 unique articles) there are a few newspaper editorials and stories featuring industry experts that expressed skepticism toward the public. An editorialist wrote in that 'people don't often understand energy, chemicals or water and it is unfortunate that scare stories about the impact of shale-gas drilling bear no relation to future reality.'

5.14 This theme of generally questioning the public ability to incorporate science into decision-making is more evident in social media sources. Celebrities and community artists who stand behind the anti-fracking campaigns are assumed to be ignorant of 'Science' (e,g, 'these artists don't know anything about hydraulic fracturing: http://t.co/zBbAZltPSa). In other examples, the public or some implied group is derided for not caring about 'facts and science', artists are targeted as 'leftists' who don't know what is 'good for America', and the American public deemed apathetic.

5.15 As noted above, the public's ability to grasp science was typically questioned in terms of the influence of corrupt research propaganda, and/or clouded judgment due to emotion, fear and anecdotes. There are numerous examples of social media posts that convey these views and that point to the corrupting influence of politics, industry interests, or 'Hollywood.' Examples include 'Politics Trumps Science', 'The haliburton loophole', and 'Science vs. Matt Damon.'

5.16 The underlying concern of these messages is that rather than deriving an agenda from scientific evidence, science is being manipulated by various actors to fit their preconceived agendas. We do not argue that this is the same thing as having observed that scientific evidence is claimed based on whether it supports an ideological position a priori. Rather, this is a portrayal of the science as corrupted or corruptible, particularly by industry or politics or the public's ability to understand the science as corruptible, as commonly the case with references to Hollywood liberals. The common denominator is that there is some kind of perceived corruption of scientific knowledge due to the agendas of economic, political, and symbolic (e.g., screen actors) agents. Such examples were also evident in newspapers: A journalist reports a protest letter as saying, 'The committee appears to be performing advocacy-based science and seems to have already concluded that hydraulic fracturing is safe.' Another editorialist writes that we should 'put the breaks on further activity until science has proven its safety - independent science, not research paid for by the industry.'

5.17 Thus, there is a widely held perception that public scientific debate must contend with propaganda and misinformation campaigns. This does not necessarily imply abandoning such debate, but it does require an ability to separate the good from the bad, or the 'real' or 'solid' from the 'fake' or 'junk' science. In many cases among the sources that favor fracking, science is posed as anti-emotional or anti-ideological by portraying the antifracking public as overly emotional and overly susceptible to scare stories. One journalist quotes a pro-fracking advocate (Brad Gill of the Independent Oil and Gas Association) as saying, 'a Hollywood actor holding a glass of cloudy water proves nothing except that fear-mongering and emotion will always trump science and logic.' See Appendix A for additional examples.

5.18 Nevertheless, against this general skepticism was a more optimistic tendency to accept the institution of science as fundamentally important to the debate while emphasizing public opinion or action. While this optimism is somewhat guarded, it is clear that distrust of science is not universal. We can distinguish between absolute distrust in science and a more conditional distrust predicated on the perceived corruption of scientific knowledge due to interference from government, industry, and media. There is tension between wanting more science in the public debate of fracking and withholding trust in science because of perceived corruption.

\section{Limitations}

6.1 This study has some limitations and results should be interpreted accordingly. First, we cannot generalize to a greater population - we do not know how people talk about fracking and science in general. We can only examine the process by which science is represented in online media posts and newspaper articles 
during the study period. As such, we have refrained from quantitative analysis that relies on sampling distribution theory. We have not reported on differences between country due to having small samples for some states and lacking location data for social media. We have chosen to include all newspaper articles from various countries in the analysis, as opposed to restricting it to the U.S. and/or the U.K. A country-by-country analysis could be an avenue for future research. Another promising avenue for future research would be to analyze comments linked to and in concert with specific news articles online. While this method may be subject to similar limitations, it could also expand in interesting ways on how active consumers of online news interpret science, evidence, and risk. The weighing of risk and benefit-particularly in terms of economy and environment-could be a fruitful analysis for understanding public decision-making.

Social media space has some inherent constraints as a forum for public debate, as in the character limitation imposed on Twitter Tweets that restricts length and inhibits a full expression of ideas. This means that long analytical essays espoused in the public opinion sections of newspapers are not finding an exact analogue in social media. This is a concern because Twitter accounts form a large share of social media conversations $(68 \%)$, as compared to public Facebook posts (16\%) that are more likely to be private and closed, or weblogs where more thoughtful essays can be submitted but are far less common (6\%). The remainder was from miscellaneous sources that include Google Plus, Reddit, Delicious, and various online forums (10\%). The trackur data collection tool has a predefined method for searching weblogs and online forums that were not openly shared, thus posing a potential limitation to our research.

6.3 The selective segment of the population that uses social media is not representative of society, as mentioned earlier. A study by PEW (2012) found that younger people (18-29) were by far the most active social media users, and that use declined linearly with age. For instance, about 86 percent of 18-29 year olds had a Facebook account, as compared with 35 percent of those 65 and older. They found women (71 percent) were more active on social media than men (62 percent). They reported that urbanites (70 percent) are more likely to be social media users as compared to rural residents (61 percent). Interestingly, the Hispanic population was the most active ethnic group, followed by black (68 percent), and white, non-Hispanic (65 percent). In terms of education, those with less than a high school diploma were least active (60 percent), and those with some college were most active (73 percent). The income demographics are not linear, as those earning under $\$ 30,000$ US were roughly as active as those making more than $\$ 50,000$ US. Those earning between $\$ 30$ and $\$ 50,000$ US were least active (62 percent). In summary, the profile most represented is young urbanite women with some college and of Hispanic descent, while those least represented include older rural white males.

6.4 We also found reasons to be selective and careful regarding the use of social media analytical tools. Our comparison of coding for favorableness toward fracking yielded a .230 Pearson's r. For the invocation of science, the two methods of coding were correlated with a Pearson's $r$ of .263. In some cases, sarcasm was not interpreted automatically, as in this example: 'What a fantastic idea! I'm sure no ill will come of it. MT @Alternet Fracking to occur 1 mile from nuclear power plant http://t.co/7yenX0QR.' However, for finding exact words, the frequency of broad topics (indicated by hashtags), and more overtly discernable trends, Modeler can be a very useful tool for text mining.

Finally, the choice to examine all available news articles and social media messages, irrespective of geographic location, means that the influence of context has not been carefully examined. Future studies might focus more exclusively on the context of particular cases, such as South Africa, and consider how contextual factors are shaping public dialogue in news print and social media sources. In addition, our analysis goals were to identify overarching themes and we therefore did not examine the specific exchanges and dialogues between individual users through a network-type of analysis. Future studies may consider a closer examination of the context that emerges from the exchanges between Tweets.

\section{Conclusion}

7.1 The simultaneous coverage of hydraulic fracturing as a boon and a bane is consistent with previous research on chiastic coverage (e.g., Ten Eyck and Deseran 2004), but the unexpected large segment of neutrality somewhat complicates this interpetation. It may be possible that it is too early in the debate for opinions and media coverage to be more polarized, and follow-up research can test this possibility. If we view the bifurcation in terms of how science is invoked, however, the notion of a chiastic media draws attention to the extreme reactions to the science of risk that has already developed. 
media fall into two broad categories: 1) a view of science as corrupt and 2) the precautionary principle. These two reactions are in turn strategies used by advocates and the opposition. Claims about science in editorials and social media posts typically follow ideological positions rather than the reverse - the 'science' that supports fracking as safe is called into question by those skeptical of fracking, while the anti-fracking position is designated as 'anti-science' by those who favor fracking. A sense of uncertainty is paradoxically engendered by the deepening of certainty on both sides and the proliferation of contradicting claims. In both forms of media, science is sometimes invoked as rational and objective to either neutralize or support emotionally-charged accounts and fears of hydro-fracturing's dangers. In other cases, however, science is viewed as a bureaucratic tool used at the will of government and business interests and easily corrupted to support ideological or interestbased positions. The limitations of science, as pertains to the nature of inference-making and deductive and inductive logic for example, are not discussed or debated in any of the forums we found. Rather, simplistic portrayals of science as good and bad, real and corrupt, are typically used. This is the case in both lengthconstrained social media posts and the longer editorials and opinion pieces.

However, some discourse emphasizes the cumulative nature of science, arguing that we need to see how the evidence stacks up. This view lends itself to the cautionary approach when it comes to decision-making. However, it may also degenerate into the ideologically-servicing views of science we find elsewhere as people come to take positions on one side of the debate or the other. We find few examples of the argument that while there are some risks, there is also evidence of alleviations of risk, and that realistic risk assessment based on science should take place. We also find few arguments that presume neutrality but assess the science conclusively. We cannot evaluate the actual decision-making process in this paper, but we note that such an approach is lacking in the editorials, news reports, and online posts.

7.4 While it is tempting to align these two reactions to uncertain science with ideological extremes - the right being more skeptical and the left being more precautionary-we do not find this conclusively in the data. Some who oppose fracking do express much cynicism. However, those who advocate for fracking are less likely to propose a wait-and-see approach, and more likely to accuse the other side as irrational. It is also clear from many newspaper accounts that a good number of citizens feel caught in the middle. What many need is a clearer conception of how science works - the cumulative and slow nature of research.

7.5 In his analysis of science in public debate that is nearly a century old and certainly predates Twitter and Facebook, John Dewey (1927) voiced strong opposition to Plato's vision of a technocracy. Instead, he called for free and full intercommunication between experts and citizens in the context of a more inclusive democracy. Citizens, for their part, would not be required to grasp all the technical details of a particular issue; Dewey (1927:209) states 'what is required is that they have the ability to judge of the bearing of the knowledge supplied by others upon common concerns.' In other words, the public will have to consider how its common concerns will be impacted by decisions of a technical nature using knowledge shared by scientists. They will learn what is necessary, but only in the absence of 'secrecy, prejudice, bias, misrepresentation, and propaganda as well as sheer ignorance' (Dewey 1927:209). Finally, Dewey (1927: 208) forcefully argues: 'The essential need, in other words, is the improvement of the methods and conditions of debate, discussion, and persuasion. That is the problem of the public' (emphasis in original).

7.6 Both journalists and members of the public express a desire to see more science in the debate over fracking, but fears are commonly expressed that scientific information is being corrupted by various political, economic, and social interests. Scientific claims are not always accepted, but rather understood with extreme skepticism and caution and as subject to bureaucratic or ideological interests. Charges of junk science are flung from both sides of the debate and in generalized ways that are hard to refute. In an era-which we will not go so far as to designate postmodern, but in which overwhelming scientific evidence can be widely questioned, as with the case of climate science - the ability to separate legitimate science from propaganda is essential. The ability of the public to navigate this task may indeed be the crucial issue. We find in comparing online social and print media that neutrality can be maintained in both sorts of forums, although print media is more likely to form the source or focus of a debate, even when picked up in the online social media, whereas online social media serves to invite audiences to participate more fully by referencing other online or local forums.

7.7 Moreover, public concerns should not be readily dismissed as being anti-science or based on emotional interpretations, even if there is reason to make such claims. As Saleh points out, 'characterizing public concerns as irrational, emotional, anti-science or anti-progress only serves to increase the intensity of concerns especially since it is often the very definition of progress itself that is being contested' (citing Kearnes et al. 2006) (234). And indeed, both critics of fracking and ambivalent or neutral parties overwhelmingly advise the cautionary approach. 
Ultimately we support Dewey's primary concern with the 'methods and conditions of debate, discussion, and persuasion' as they pertain to fracking, and in a broader sense with respect to any matter of a scientifically technical nature. This implies a simultaneous endorsement of strategies that (a) would limit the power of propaganda to pose as science, (b) improve the public's ability to distinguish sound scientific research from propaganda, and (c) encourage debate that focuses on specific studies rather than sweeping generalized claims that the science 'is in' and therefore closed and complete. A more pragmatic position-echoed to some degree by contemporary theorists such as Wynne, Beck and Norton-is to start from the assumption that science remains open and is always incomplete, while recognizing the sway of evidence. The ways in which online media is both partially sourced and commented upon by the public complicate such goals. Nonetheless, given the level of uncertainty that exists among experts and technocrats during the time period of examination, ambivalence makes sense. In a risk society, uncertainty among scientists, technocrats, and the public is the norm (Wynne 1988; Beck 1995). The dangers as we see them is in the tendency to revert to claims reporting without understanding or scientific context (common in news articles particularly from the U.S.), and in the ease with which scientific evidence may be dismissed if the uncertainty is interpreted rightly or wrongly as corruptible or ideological (common in our online media sources). The latter seems to feed upon the former.

Finally, since we find that claims about the science often serve to justify a preset list of beliefs about the safety or dangers of fracking, the cynical public is often a response to ideological differences and not science itself. This cynicism emerges regardless of the type of media or the position supported. Future research should continue to interrogate this bi-construction of science as the antidote to emotion and irrationality on one hand, and on the other as corruptible and therefore possibly all too easily dismissed.

\section{Appendix A: Additional Examples}

\section{For Section Uncertainty}

1. A grassroots group is filing a complaint against Penn State for publishing junk science pro \#fracking research papers. http://t.co/x8PMOAl6> [Record 11380, Social Media]

2. The USA's $\mathrm{CO} 2$ emissions are now at their lowest levels in 20 years, because of natural gas, a sluggish economy, and the retirement of 100-200 coal-fired power plants due to an EPA regulatory onslaught that is based heavily on agenda-driven, slipshod and even fraudulent and illegal science. [Record 6890, Social Media]

3. It's almost like the scumbag enviro-mystic who oppose Hydraulic fracturing are liars?! They make it sound like the earth will split open and swallow cities whole, yet its barely enough to feel. Gee, so surprised. [Record 129, Social Media]

4. @LakeAinslie What a shame enviro hypocrits still frothing about fracking shale gas elsewhere while ignoring reality @ LA \& Nova Scotia. [Record 10892, Social Media]

5. The worry is that the chemicals used in fracking sometimes contaminate water supplies. No one has conclusively demonstrated such contamination, but there has been shockingly little study of the issue - and considerable evidence that political interference has discouraged it. [No. 591. S.A. 12 May, 2011. Editorial.]

6. Your article stating that legislative action on hydraulic fracking should wait until the Environmental Protection Agency report is complete ignores groundwater's importance in this arid climate. Given that groundwater quality is not easy to restore and often cannot be restored, waiting three years to take action can cause serious and permanent impairment. Until there is conclusive evidence that fracking will not impair groundwater, our policy should be precautionary to protect this resource. [No. 643. U.S. 27, April 2011. Editorial.]

7. Attwood urges public participation in all Ireland Hydraulic Fracturing ... Utility Products Commenting on the public consultation Minister Attwood said: "I have repeatedly said that it is essential to get the science right." [Record 8539, Social Media]

8. San Francisco Chronicle Governor: Science drives Wyo. gas study UPI.com Analysis of deep monitoring wells by the Environmental Protection Agency in a Wyoming aquifer revealed glycols and other synthetic chemicals associated with hydraulic fracturing. Wyoming Gov. Matt Mead said he'd take a wait-and-see approach [Record 6628, Social Media] 
1. @leObreezy Plz RT energy news The science \& economics of \#fracking says yes to fracking [Record 27515, Social Media]

2. RT @saeverley: Anti-fracking scientist says a moratorium on fracking is a basic human right. Because, you know, science. http://t.co/1sEjWAkJmm [Record 28433, Social Media]

3. Science is catching up with \#fracking, \#shale \#gas drilling and injection well problems. Not a pretty picture. http://t.co/tbzqhKU3S6 [Record 19003, Social Media]

4. Committed to Monitoring? We are committed to monitoring the issue and... currently there is no scientific data associating hydraulic fracturing with earthquakes [Record 3964, Social Media]

5. The controversial practice of hydraulic fracturing to extract natural gas does not pose a high risk for triggering earthquakes large enough to feel, but other types of energy-related drilling can make the ground noticeably shake, a major government science report concludes. Even those man-made tremors large enough to be an issue are very rare, says a special report by the National Research Council [Record 127, Social Media]

6. The independent experts included MacArthur genius award-winner and chemist Wilma Subra, water test expert Steven Penningroth, toxicologist Theo Colborn, and SUNY Oneonta chemist Ron Bishop. All concluded that methane levels were dangerous to residents and pointed at the long chain of science implicating Cabot Oil and Gas and faulty gas wells as the source of the thermogenic gas. [Record 39, Social Media]

7. Frackers dodge responsibility for earthquakes, science be damned http://t.co/e4yzjv169H \#fracking \#shale> [Record 8903, Social Media]

8. The Duke study found no evidence to support the notion that the chemical fracking fluids have contaminated the water supply. / Still, scientists point to the methane presence as an alarming trend. [No. 525. U.S. 1 June, 2011. Non-editorial.]

9. SCIENTISTS in the US have found almost all of the 596 different chemicals used during the fracking process currently being considered for gas exploration in the Karoo are extremely hazardous to human health, causing cancer, birth defects and even sterility. [No. 331. S.A. 16, July, 2011. Non-editorial.]

10. In their report, E.P.A. officials also wrote that Mr. Parsons' case was highlighted as an "illustrative" example of the hazards created by this type of drilling, and that legal settlements and nondisclosure agreements prevented access to scientific documentation of other incidents. [No. 267. U.S. 4 August, 2011. Non-editorial.]

11. Asked about the danger of long-term leaching of this fluid into aquifers, he answered once again that no tests had showed that it could occur. [No. 789. S.A. 21, March, 2011. Non-editorial.]

12. "There is no evidence to support this mechanism as the cause, none of the chemicals used in the fracking process have turned up in people's drinking water, none," he said, echoing Alexander's earlier statement.

[No.575. Canada. 16 May, 2011. Non-editorial.]

13. One advertisement reads: "Shell will provide full compensation to any landowner who can show evidence of a direct negative impact or loss on their land as a result of our activities."... "Shell has a $\$ 100$ billion kitty to draw from, and you think we have half a chance of proving not just a negative impact, but a direct negative impact?" said Dr Peter Baker, a landowner from Richmond who attended the meeting. [No. 777. S.A. 24 March, 2011. Non-editorial.]

14. It seems to me he is trying to pre-spin the story because the draft of a new study plan is about to be released next month. When you see kitchen faucets with running water on fire, that is pretty good evidence of gas contamination. There is more than one example of this, and they are easily found online. [No. 827. U.S. 24, February, 2011. Editorial.]

\section{For Section The Corruptibility of Science}

1. "Everyone's got to take a deep breath and say, 'Let's get back to the facts and science,"' he says...He's right. Environmentalists especially should respect the process... They need to tone down the "no fracking way" 
rhetoric... [No. 527. U.S. 31, May, 2011. Editorial.]

2. Guest post: The failure of an anti-fracking fantasy http://t.co/HgXRvyt6uy> Because facts \& science just aren't sexy. \#natgas \#fracking [Record, Social Media]

3. RT @grist: Most Americans don't give a frack about fracking http://t.co/STPcPi1sBu> [Record 9561, Social Media]

4. RT @SocialistViews: Politics and corporate interest, not science, will likely decide whether NY will permit \#fracking http://t.co/beZn7In5> [Record 10599, Social Media]

5. After all, who knows more about the dangers and ethics of fracking than someone who is in the business of fracking? \#expert \#fakescience [Record 12142, Social Media]

6. The haliburton loophole http://t.co/S4Arjj60BI> The war on science, \#fracking \#nbpoli \#bcpoli \#idlenomore \#INM" [Record 30657, Social Media]

7. Washington Times Fracking flick channels science fiction. Washington Times If you don't have the facts on your side, make some up. That's Hollywood's typical scheme for pushing its left-wing views on American audiences. Tinseltown's "Promised Land" puts a heavy thumb on the scale in favor of Big Green [Record 7731, Social Media]

8. Science vs. Matt Damon Urban Legends Concerning Fracking Matt Damon has recently released a new movie, called Promised Land, which raises environmental concerns over hydraulic fracturing [fracking]... http://disorderedliberty.com/?p=1104> [Record 2415, Social Media]

9. "The committee appears to be performing advocacy-based science and seems to have already concluded that hydraulic fracturing is safe," scientists at 22 universities in 13 states said in a letter to Mr. Chu Wednesday in anticipation of the report's release. "We believe that the best science should be done first to determine whether increased unconventional natural gas production is sufficiently safe - from the individual water well to climate impact and that policy should follow." [No. 237. U.S. 11, August, 2011. Non-editorial.]

10. And put the breaks on further activity until science has proven its safety - independent science, not research paid for by the industry and published in an Irving-owned newspaper. [No. 439. Canada. 15, June 2011. Editorial.]

11. "A Hollywood actor holding a glass of cloudy water proves nothing except that fear-mongering and emotion will always trump science and logic," he said, taking aim at the recent critical TV documentary "Gasland," by Josh Fox. [No. 925. U.S. 14 September, 2010. Non-editorial.]

12. Richard Downey of Otego, a member of the Unatego Area Landowners Association, said he's not opposed to the federal study, but wants it to be objective. / "Go with the science, not the scare tactics," he said. [No. 931. U.S. 10 September, 2010. Non-editorial.]

13. Listening to \&\#64;mruff221 discuss \#fracking and renewable energy. Bringing culture, science \& business together to create solutions. \#tnp2012 [Record 12674, Social Media]

14. Join big thinkers to explore how \#science can inform dialogue \& decision making on \#fracking @UCSUSAs Forum: http://t.co/2pfGukViXk [Record 27518, Social Media]

\section{References}

ADAM, B., U. Beck and J. van Loon (2000) The Risk Society and Beyond: Critical Issues for Social Theory, London: Sage.

ANDERSON, A. A., D. A. Scheufele, D. Brossard, and E. A. Corley (2011) 'The role of media and deference to scientific authority in cultivating trust in sources of information about emerging technologies', 
International Journal of Public Opinion Research, Vol. 24, Issue 2, p.225-37.

BBC (2011) Fracking tests near Blackpool 'likely cause' of tremors. Retrieved 22 July, 2012 from http://www.bbc.co.uk/news/uk-england-lancashire-15550458.

BECK, U. (1995) Ecological Politics in an Age of Risk Cambridge: Polity Press.

BECK, U. (2009) World at Risk, Cambridge: Polity Press.

BROWN, V. (2007) 'Industry Issues: Putting the Heat on Gas,'Environ Health Perspect Vol. 115, Issue 2, p. A76.

BECK, Ulrich and Christoph Lau. 2005. 'Second modernity as a research agenda: theoretical and empirical explorations in the "meta-change" of modern society,' The British Journal of Sociology, Vol 56, Issue 4, p. 525-557.

CHARMAZ, K. (2006) Constructing Grounded Theory: A Practical Guide through Qualitative Analysis, Thousand Oaks, CA: Sage.

CHRISTIDOU, V., K. Dimopolous, and V. Koulaidis (2004) 'Constructing social representations of science and technology: The role of metaphors in the press and the popular science magazines', Public Understanding of Science, Vol. 13, p. 347-362.

COOPER, G. and M.y Ebeling (2007) 'Epistemology, structure and urgency: The sociology of financial and scientific journalism', Sociological Research Online, Vol. 12, Issue 3.

DEUZE, M. (2005) 'Participation, remediation, bricolage: Considering principal components of a digital culture', The Information Society: An International Journal, Vol. 22, Issue 2, p. 63-75.

DEWEY, J. (1927) The Public \& its Problems, Athens, OH: Ohio University Press.

ESTERBERG, K. G. (2002) Qualitative Methods in Social Research, Boston: McGraw Hill.

EVENSEN, D. T., C. E. Clarke, and R. C. Stedman (2013) 'Fractured discourse: Social representations in newspaper coverage of shale gas development', Rural Sociological Society meetings, 2013.

FITZGERALD, S. T. and B. A. Rubin (2010) 'Risk Society, Media, and Power: The Case of Nanotechnology,' Sociological Spectrum Vol. 30, p. 367-402.

GUNSALLUS, A., M. A. Martin, and D. K. McLaughlin (2013) 'Work and family trade-offs of fathers in gas-related occupations in rural Pennsylvania', Rural Sociological Society meetings, 2013.

IEA (2012) Golden rules for a golden age of gas, World Energy Outlook Special Report on Unconventional Gas, OECD, p. 18-27.

KEARNES, M., R. Grove-White, P. Macnaghten, J. Wildon, and B. Wynne (2006) 'From bio to nano: learning lessons from the UK agricultural biotechnology controversy', Science as Culture, Vol. 15, Issue 4, p. 291307.

LEVIDOW, L. (2002) Regulation: Science or Politics? Science \& Public Affairs, April issue, p. 22-3.

LULOFF, A. E., F. K. Willits, G. L. Theodori (2013) 'Residents' views of natural gas drilling in the Pennsylvania marcellus shale, 2009 and 2012', Rural Sociological Society meetings, 2013.

LUSTGARTEN, A. (2011) Climate benefits of natural gas may be overstated, Pro Publica. Retrieved 15 January, 2014 from http://pop.subduction.net/Storage\%20for\%20News\%20Articles/20

11/January\%202011/Climate\%20Benefits\%20of\%20Natural\%20Gas\% 20May\%20Be\%20Overstated,\%201-25-11.pdf.

MONTGOMERY, C.T. and M.B. Smith (2010) 'Hydraulic fracturing: history of an enduring technology',Journal of Petroleum Technology, Vol. 62, p. 26-32.

NEWS and RESEARCH Communications (NRC). 2013. Survey finds ignorance of 'fracking' despite emerging importance, Published 23 December, 2013 (no author). Oregon State University. Retrieved 15 January, 2014 from http://oregonstate.edu/ua/ncs/archives/2013/dec/survey-finds-widespread- ignorance\%E2\%80\%9Cfracking\%E2\%80\%9D-despite-emerging-importance.

NORTON, B. G. (2005) Sustainability: A Philosophy of Adaptive Ecosystem Management, Chicago: University of 
Chicago Press.

PEW RESEARCH CENTER. 2012. Internet \& American Life Project Post-Election Survey. November 9, 2012.

PRIEST, S. H. (1994) Structuring Public Debate on Biotechnology: Media Frames and Public Response,'Science Communication, Vol. 16, p. 166-79.

PRIEST, S. H. (2008) 'North American Audiences for News of Emerging Technologies: Canadian and US Responses to Bio- and Nanotechnologies,' Journal of Risk Research Vol. 11, p. 877-89.

REISCH, H. and D. J. Speigelhatlter (2011) "Careless Pork Costs Lives": Risk stories from science to press release to media, Health, Risk \& Society', Vol. 13, Issue 1, p. 47-64.

SALEH, A. (2008) 'The fourth estate and the fifth branch: The news media, GM risk, and democracy in Australia', New Genetics and Society, Vol. 27, Issue 3, p. 233-50.

SCHAFER, M. S. (2011) 'Sources, characteristics and effects of mass media communication on science: A review of the literature, current trends and areas for future research', Sociology Compass, Vol. 5, Issue 6, p.399-412.

STRAUSS, A. and J. Corbin (1998) 'Grounded Theory Methodology: An Overview', Pp. 158-83 inStrategies of Qualitative Inquiry, edited by N. K. Denzin and Y. S. Lincoln, Thousand Oaks, CA: Sage.

TEN EYCK, TOBY and F. Deseran. 2004. 'Oyster Coverage: Chiastic News As a Reflection of Local Expertise and Economic Concerns.' Sociological Research Online, Vol. 9, Issue 4, p. 1-1.1P.

TULLOCH, J. C. and J. O. Zinn (2011) 'Editorial: Risk, health and the media',Health, Risk \& Society, Vol. 13, Issue 1, p. 1-16.

TULLOCH, J. C. and J. O. Zinn (2011) 'Editorial: Risk, health and the media',Health, Risk \& Society, Vol. 13, Issue 1, p. 1-16.

WANDER, P. C. and D. Jaehne (2000) 'Prospects for a "Rhetoric of Science"',Social Epistemology, Vol. 14, Issue 2-3, p.211-33.

WYNNE, B. (1988) 'Unruly technology: Practical rules, impractical discourses and public understanding',Social Studies of Science, Vol 18, Issue 1, p. 147-67.

ZOBACK, M., S. Kitasei, B. Copithorne (2010) Addressing the environmental risks from shale gas development. Briefing Paper 1, WorldWatch Institute, Natural Gas and Sustainable Energy Initiative. 